\title{
Reduced $\mathrm{CeO}_{2}(111)$ ordered phases as bulk terminations: Introducing the structure of $\mathrm{Ce}_{3} \mathrm{O}_{5}$
}

\author{
G. E. Murgida, ${ }^{1, *}$ V. Ferrari, ${ }^{1}$ A. M. Llois, ${ }^{1}$ and M. V. Ganduglia-Pirovano ${ }^{2}$ \\ ${ }^{1}$ Centro Atómico Constituyentes, GIyA, CNEA, San Martín, Buenos Aires, Argentina and Consejo Nacional de Investigaciones \\ Científicas y Técnicas, C1033AAJ Buenos Aires, Argentina \\ ${ }^{2}$ Instituto de Catálisis y Petroleoquímica, Consejo Superior de Investigaciones Científicas, 28049 Madrid, Spain
}

(Received 6 April 2018; revised manuscript received 26 July 2018; published 31 August 2018)

\begin{abstract}
Reduced ceria $\left(\mathrm{CeO}_{2-x}\right)$ has a rich phase diagram comprising a variety of bulk phases with stoichiometries ranging from $\mathrm{CeO}_{2}$ to $\mathrm{Ce}_{2} \mathrm{O}_{3}$ as the reduction conditions are increased. Some observed reduced ceria (111) surface reconstructions are terminations of stable bulk phases, such as $\sqrt{7} \times \sqrt{7}$, whereas others are not associated with any known stable phases, namely, $\sqrt{7} \times 3,3 \times 3$, and $\sqrt{3} \times \sqrt{3}$. In this paper, we analyze different periodic reconstructions of reduced ceria (111) surfaces within a theoretical framework. We describe the surfaces of stable bulk phases and elucidate the structure of the observed periodicities not corresponding to terminations of known stable bulk phases. Extending the $3 \times 3$ and $\sqrt{3} \times \sqrt{3}$ terminations into a bulk structure, we find a new quasistable $\mathrm{Ce}_{3} \mathrm{O}_{5}$ bulk phase, which explains both periodicities. On the contrary, the $\sqrt{7} \times 3$ surface structure cannot be extended into a bulk but stabilizes as a very thin overlayer. We also analyze other reported bulk structures with stoichiometry close to the $\mathrm{Ce}_{3} \mathrm{O}_{5}$ one, namely, the $C$-type $\mathrm{Ce}_{2} \mathrm{O}_{3+\delta}$ bulk phase, which cannot describe the observed terminations. Our goal is to provide a unified picture to describe the road map of $\mathrm{CeO}_{2-\delta}(111)$ surface reconstructions and, when possible, their relationship to reduced ceria bulk phases.
\end{abstract}

DOI: 10.1103/PhysRevMaterials.2.083609

\section{INTRODUCTION}

Due to the singular capability of ceria $\left(\mathrm{CeO}_{2}\right)$ to easily absorb and release oxygen, it is widely employed in redox catalytic reactions [1-4] necessary for applications, such as hydrogen production, and for its most ubiquitous application, automotive exhaust treatment [5-8]. Furthermore, ceria-based materials were proposed and used for a variety of applications, such as fuel cells $[9,10]$, sensors $[11,12]$, gate oxides in microelectronic devices [13], and nonvolatile resistive memories [14]. In these applications, both oxygen vacancies and the charge left behind upon the vacancy formation play a crucial role. Therefore, it is of the upmost importance to obtain a detailed understanding of the density and distribution of oxygen vacancies as well as the charge localization to tailor the functionality of ceria-based materials in applications.

Upon the formation of an oxygen vacancy in ceria, two electrons localize in two Ce cations, changing their valence number formally from $\mathrm{Ce}^{4+}$ to $\mathrm{Ce}^{3+}$, preferably at $\mathrm{Ce}$ sites which are next-nearest neighbors to the vacancy [15-26]. Under increasing reducing conditions, the stoichiometry is gradually changed in a reversible way from $\mathrm{CeO}_{2}$ to the most reduced state $\mathrm{Ce}_{2} \mathrm{O}_{3}$. A rich phase diagram was predicted for reduced bulk ceria [27-31], nonetheless only a few stable bulk phases were experimentally found and described in detail. Namely, the fluorite-related phases $\mathrm{Ce}_{11} \mathrm{O}_{20}\left(\mathrm{CeO}_{1.81}\right), \mathrm{Ce}_{7} \mathrm{O}_{12}\left(\mathrm{CeO}_{1.71}\right)$, and the cubic-type $C-\mathrm{Ce}_{2} \mathrm{O}_{3}$ (bixbyite), as well as the hexagonal-type $A-\mathrm{Ce}_{2} \mathrm{O}_{3}$ phases $\left(\mathrm{CeO}_{1.5}\right)$ [21,32]. In addition, a $C$-type $\mathrm{Ce}_{2} \mathrm{O}_{3+\delta}$ phase with a composition range from $\mathrm{CeO}_{1.66}$ to $\mathrm{CeO}_{1.68}$ has been reported [27,32].

\footnotetext{
*Corresponding author: murgida@tandar.cnea.gov.ar
}

Ceria surfaces are of particular importance due to their chemical and reactivity properties as stand-alone catalysts $[4,33,34]$ or as catalyst support [35-38] and thus have been the subject of intensive works during the past years especially the (111) surface because it is the most stable one. Since the pioneering work of Nörenberg and Briggs [39], scanning tunneling microscopy and atomic force microscopy (AFM) techniques have been employed to observe the ordering of the near-surface oxygen vacancies which form isolated defects, clusters, or periodic structures [40-47]. For example, Torbrügge et al. found experimental evidence of a $2 \times 2$ ordering of subsurface vacancies at the (111) surface of ceria [41]. This result was later confirmed by theoretical works evidencing the subsurface preference of oxygen vacancies and explaining the stability of the periodic array [17]. After that, other periodic arrangements of vacancies at reduced ceria surfaces were observed. Using low-energy electron-diffraction (LEED) techniques on (111) surfaces obtained under different growth and reduction conditions, surface reconstructions with periodicities $\sqrt{7} \times \sqrt{7}, 3 \times 3,4 \times 4$, and $1 \times 1$ were reported [42-47]. More recently, the $\sqrt{7} \times 3$ and $\sqrt{3} \times \sqrt{3}$ periodicities were also observed in reduced thick films of ceria using noncontact AFM microscopy [48].

Some of the periodic reconstructions observed on reduced ceria (111) surfaces can be traced back to surface planes of reduced bulk ceria phases. For instance, the $\sqrt{7} \times \sqrt{7}$ and $4 \times 4$ reconstructions have been attributed to surface terminations of $\mathrm{Ce}_{7} \mathrm{O}_{12}(111)$ and $C-\mathrm{Ce}_{2} \mathrm{O}_{3}$, respectively. On the contrary, the $3 \times 3, \sqrt{7} \times 3$, and $\sqrt{3} \times \sqrt{3}$ periodicities cannot be assigned to any known stable bulk structure. In this paper we show that the $3 \times 3$ and the $\sqrt{3} \times \sqrt{3}$ periodicities can be described as (111) terminations of a metastable bulk phase with $\mathrm{Ce}_{3} \mathrm{O}_{5}\left(\mathrm{CeO}_{1.67}\right)$ stoichiometry which is different 
from the previously reported $C$-type $\mathrm{Ce}_{2} \mathrm{O}_{3+\delta}$ phase [32]. In contrast, we show that the oblique $\sqrt{7} \times 3$ structure, which has the same $\mathrm{Ce}_{3} \mathrm{O}_{5}$ stoichiometry, does not correspond to any crystallographic termination of that metastable bulk structure. Therefore, the aim of this paper is twofold. On one hand, to model the surface distributions of oxygen vacancies with various periodicities, several of which have been experimentally observed for different degrees of ceria reduction and to analyze their relative stability using density functional theory plus $U$ $(\mathrm{DFT}+U)$. On the other hand, to relate the observed surface reconstructions to appropriate bulk phases when possible. We undertake this paper with the final goal of providing a unified picture to describe the road map of surface reconstructions and their relationship to reduced ceria bulk phases.

\section{METHODS}

We use the spin-polarized DFT in the DFT $+U$ approach with the gradient-corrected approximation (GGA) PerdewBurke-Ernzerhof (PBE) functional [49]; we only consider high spin states. The Kohn-Sham equations are solved via the projected augmented-wave method using the implementation of the Vienna $a b$ initio simulation package (VASP) [50]. In the DFT $+U$ calculations we use $U_{\text {eff }}=4.50 \mathrm{eV}$ [51] for the Ce $4 f$ states [52,53], hereinafter referred to as $U$. For Ce atoms, the $5 s, 5 p, 6 s, 4 f$, and $5 d$ states are treated as valence states, whereas oxygen valence is given by the $2 s$ and $2 p$ states. A plane-wave cutoff energy of $400 \mathrm{eV}$ is used. We note that questions regarding the proper way for deriving the best value for the $U$ parameter are still under debate [53-55]. Nonetheless, most DFT $+U$ studies of reduced ceria-based systems agree that $U$ values in the range of 4.5-6.0 eV with the GGA are suitable $[16,21,53,56-58]$. However, one should bear in mind that there is in general no unique $U$ value that gives a reasonable account of all systems' properties $[59,60]$.

To model reduced $\mathrm{Ce}_{x} \mathrm{O}_{y}$ overlayers on $\mathrm{CeO}_{2}(111)$, we use supercells containing (111)-oriented slabs of fluorite ceria with up to 18 atomic layers (i.e., six O-Ce-O trilayers) and a vacuum region of $13 \AA$. We employ the calculated equilibrium lattice constant of bulk ceria $5.485 \AA$ [17]. The optimization of the $\mathrm{Ce}_{x} \mathrm{O}_{y} / \mathrm{CeO}_{2}$ (111) structures consists of two steps. First, the location of the vacancies needed to accommodate a given stoichiometry is optimized taking into account certain ordering rules ( $\mathrm{R} 1-\mathrm{R} 3)$ as described in the following sections, but the location of the excess electrons $\left(\mathrm{Ce}^{3+}\right)$ is not simultaneously optimized, i.e., the excess charge is localized at cationic sites, but its distribution may not correspond to the lowest-energy structure for each vacancy configuration. Next, for the best vacancy configuration obtained in the previous step, the distribution of the excess electrons is fully optimized, keeping the location of the vacancies fixed. Ionic relaxations are performed until all forces are smaller than $0.01 \mathrm{eV} / \AA$ while keeping the unit cell and the atomic positions of the bottom $\mathrm{CeO}_{2}$ trilayer fixed. Moreover, to achieve different localizations of the $\mathrm{Ce}^{3+}$ ions, we use a two-step relaxation procedure. First, the intended $\mathrm{Ce}^{3+}$ ions are replaced by $\mathrm{La}^{3+}$ ions, and an ionic relaxation is performed. Then, Ce ions are placed back into the La sites, and the structure is relaxed again.

The $\mathrm{Ce}_{3} \mathrm{O}_{5}$ and $\mathrm{Ce}_{32} \mathrm{O}_{53}$ ( $C$-type $\mathrm{Ce}_{2} \mathrm{O}_{3+\delta}$ ) bulk structures are first modeled starting from ceria supercells with the appropriate vacancies and allowing for ionic relaxation of all atoms with fixed unit cells as derived from the fluorite structure (termed $\mathrm{Ce}_{x} \mathrm{O}_{y}$-like structures, using the same notation as in Ref. [21]). The localization of the excess electrons is also optimized. In a second step, in order to evaluate the stability of these bulk structures, we further perform a full geometry optimization of each unit cell for the energetically preferred $\mathrm{Ce}^{3+}$ localization obtained in the previous step (noted as $\mathrm{Ce}_{x} \mathrm{O}_{y}$-real structures, cf. Ref. [21]).

The Brilloiun zones are sampled using a $(6 \times 6 \times 1)$ Monkhorst-Pack grid for the $1 \times 1$ ceria (111) surface, a $(4 \times$ $4 \times 1)$ grid for the $\sqrt{3} \times \sqrt{3}$ phase, and a $(2 \times 2 \times 1)$ grid for the surface structures with $3 \times 3$ and $\sqrt{7} \times 3$ periodicities, whereas for the $\mathrm{Ce}_{3} \mathrm{O}_{5}$ and $\mathrm{Ce}_{32} \mathrm{O}_{53}\left(C\right.$-type $\left.\mathrm{Ce}_{2} \mathrm{O}_{3+\delta}\right)$ bulk unit cells, we use a $(3 \times 3 \times 3)$ grid.

The average vacancy formation energy $\left(E_{v}\right)$ is calculated as

$$
E_{v}=\frac{1}{m}\left[E\left(\mathrm{Ce}_{n} \mathrm{O}_{2 n-m}\right)+\frac{m}{2} E\left(\mathrm{O}_{2}\right)-E\left(\mathrm{Ce}_{n} \mathrm{O}_{2 n}\right)\right] \text {, }
$$

where $E\left(\mathrm{Ce}_{n} \mathrm{O}_{2 n-m}\right)$ and $E\left(\mathrm{Ce}_{n} \mathrm{O}_{2 n}\right)$ are the total energies of the reduced and unreduced unit cells, $m$ and $n$ are the number of $\mathrm{Ce}$ atoms and $\mathrm{O}$ vacancies in the cell, respectively, and $E\left(\mathrm{O}_{2}\right)$ is the total energy of the isolated $\mathrm{O}_{2}$ molecule in the triplet state. The latter is calculated using an orthorhombic box $[(12 \times 13 \times$ 14) $\left.\AA^{3}\right]$ with $\Gamma$-point sampling of the Brillouin zone.

To evaluate the stability of bulk phases as a function of temperature and oxygen pressure, we calculate the change in the Gibbs free energy [21],

$$
\Delta \gamma(T, p)=\frac{N_{v}}{V}\left[E_{v}+\Delta \mu_{\mathrm{O}}(T, p)\right],
$$

being $N_{v}$ and $V$, respectively, the number of vacancies and the volume of the unit cell. $\Delta \mu_{\mathrm{O}}(T, p)=\frac{1}{2}\left[\mu_{\mathrm{O}_{2}}(T, p)-E_{\mathrm{O}_{2}}\right]$ is the variation of the oxygen chemical potential with respect to the total energy of an isolated molecule at $T=0 \mathrm{~K}$. The chemical potential is related to actual temperature and pressure conditions by assuming that the system is in thermodynamic equilibrium with the gas phase. As the surrounding $\mathrm{O}_{2}$ atmosphere is assumed to form an ideal gas reservoir, the expression $\mu_{\mathrm{O}_{2}}(T, p)=\left[\mu_{\mathrm{O}_{2}}\left(T, p^{\circ}\right)+R T \ln \left(p / p^{\circ}\right)\right]$ with $\mu_{\mathrm{O}_{2}}\left(T, p^{\circ}\right)=\left[H\left(T, p^{\circ}\right)-H\left(0 \mathrm{~K}, p^{\circ}\right)\right]-T S\left(T, p^{\circ}\right)$ is used where $p^{\circ}$ is the pressure of a reference state $\left(p^{\circ}=1 \mathrm{~atm}\right)$. In order to translate $\Delta \mu_{\mathrm{O}}(T, p)$ into a temperature scale at a given pressure, tabulated values for the enthalpy $H$ and entropy $S$ are employed [61]. We note that, for the evaluation of the stability of reduced surface phases (see Sec. S2 of the Supplemental Material [62]), we calculate the change in the Gibbs free energy per unit area $A$, i.e., $\Delta \gamma(T, p)=$ $N_{v} / A\left[E_{v}+\Delta \mu_{\mathrm{O}}(T, p)\right]$, where $A$ is the area of the unit cell.

\section{ORDERED PHASES AT REDUCED $\mathrm{CeO}_{2}(111)$ SURFACES}

Experimental work has shown that oxidized $\mathrm{CeO}_{2}(111)$ surfaces exhibit a $1 \times 1$ atomic structure (cf. Fig. 1) [39,40,42$45,48]$. As mentioned above, some recently observed annealed ceria (111) surfaces exhibit periodicities that correspond to $\{111\}_{\mathrm{F}}$ surfaces of $\mathrm{CeO}_{2-\delta}$ stable bulk phases where the "F" subscript stands for the fluorite conventional cell of ceria. This is the case for the $\sqrt{7} \times \sqrt{7}[42-44,46,48]$ and $4 \times 4[42-45]$ 


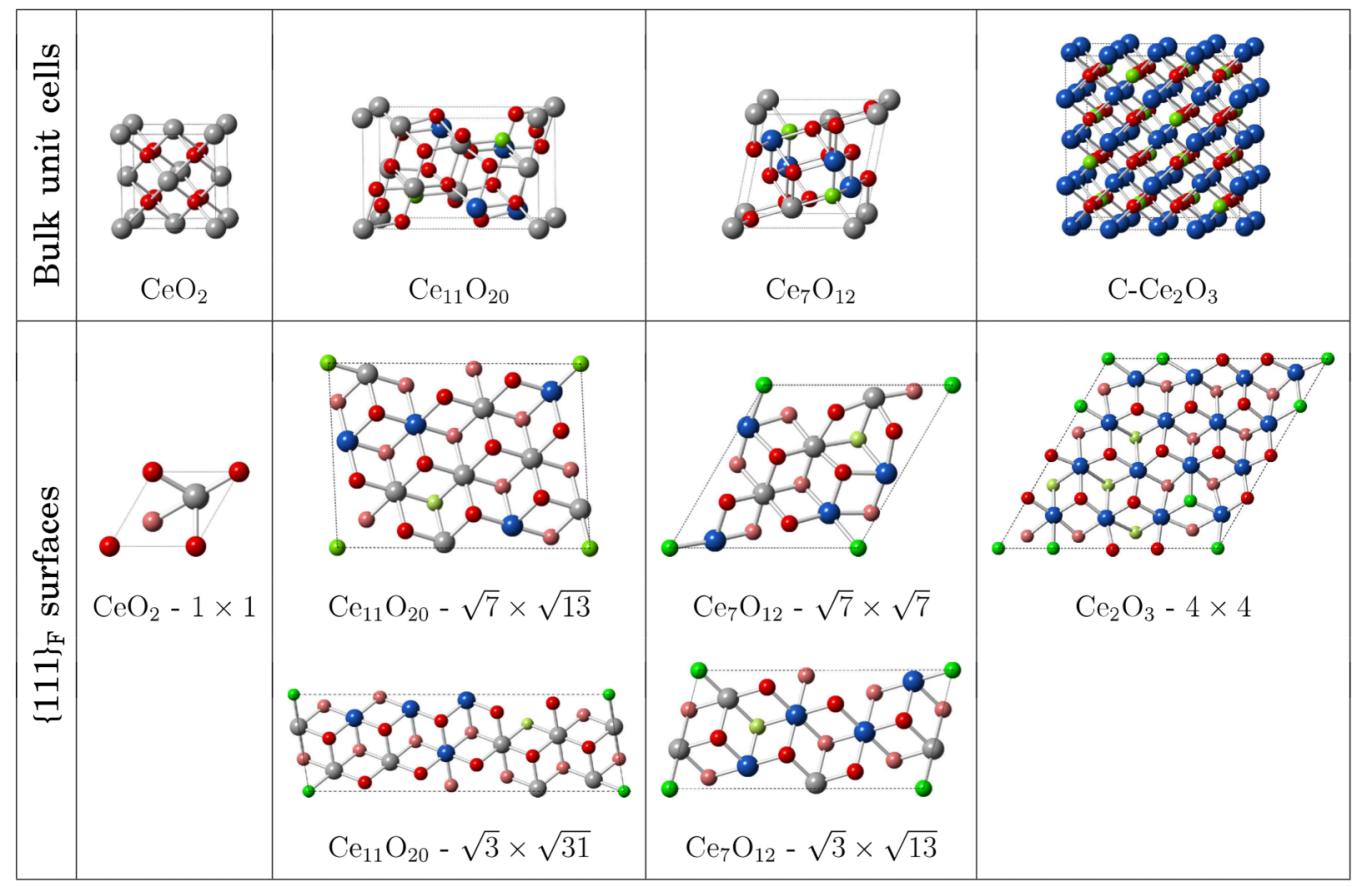

FIG. 1. Top row: Unit cells of $\mathrm{CeO}_{2-\delta}$ bulk phases. Oxygen atoms (vacancies) are represented by red (green) small balls, respectively. $\mathrm{Ce}^{4+}\left(\mathrm{Ce}^{3+}\right)$ ions are depicted as gray (blue) big balls. Bottom row: Trilayers composed of O-Ce-O layers corresponding to $\{111\}_{\mathrm{F}}$ terminations for each stable bulk phase in the top row. For clarity, oxygen ions and vacancies in the third layer are represented with a lighter color compared to the atoms in the first layer. For simplicity, the structures are sketched without the slight distortion with respect to the ideal fluorite sublattice.

periodicities, which can be understood as surface terminations of $\mathrm{Ce}_{7} \mathrm{O}_{12}$ and $C-\mathrm{Ce}_{2} \mathrm{O}_{3}$, respectively. Conversely, there are other observed periodicities that cannot be ascribed to surfaces of any known stable bulk structure, namely, the $3 \times 3$ [43-45], $3 \times \sqrt{7}$ [48], and $\sqrt{3} \times \sqrt{3}$ [48] ones. We note here that upon extensive reduction of the $\mathrm{CeO}_{2}$ (111) surfaces the appearance of a $1 \times 1$ reconstruction has been observed and ascribed to the (0001) termination of the $A-\mathrm{Ce}_{2} \mathrm{O}_{3}$-hexagonal bulk structure [48,63-65].

We start by describing all possible nonequivalent $\{111\}_{\mathrm{F}}$ surfaces of known fluorite-related bulk phases and, afterwards, we focus on the observed $3 \times 3,3 \times \sqrt{7}$, and $\sqrt{3} \times \sqrt{3}$ periodicities, which cannot be linked to surfaces of any known stable bulk.

\section{A. Surfaces associated with stable $\mathrm{CeO}_{2-\delta}$ bulk phases}

Upon annealing bulk ceria, four stable reduced structures have been reported, $\mathrm{Ce}_{11} \mathrm{O}_{20}$ (triclinic, $P \overline{1}$ space group), $\mathrm{Ce}_{7} \mathrm{O}_{12}$ (trigonal, $R \overline{3}$ space group), and, finally, $\mathrm{Ce}_{2} \mathrm{O}_{3}$ in two distinct phases, namely, bixbyite cubic $C$-type $(C 2 / \mathrm{m})$ and hexagonal $A$-type $(P \overline{3} m 1)[31,32,66,67]$. From a geometric point of view, the crystal structures of $\mathrm{Ce}_{11} \mathrm{O}_{20}, \mathrm{Ce}_{7} \mathrm{O}_{12}$, and $\mathrm{Ce}_{2} \mathrm{O}_{3}$ bixbyite can be easily derived from the $\mathrm{CeO}_{2}$ structure by removing selected oxygen atoms and allowing for lattice relaxations which turn out to be small [21]. Therefore, these reduced structures can be considered as sublattices of $\mathrm{CeO}_{2}$ fluorite. The primitive vectors and the sites of the oxygen vacancies of such sublattices are shown in Table I. For completeness, we include in this table the $\mathrm{Ce}_{3} \mathrm{O}_{5}$ bulk structure, which will be presented and discussed in the next section. We note here that the hexagonal $\mathrm{Ce}_{2} \mathrm{O}_{3}$ emerges after large structural relaxations with no resemblance to any $\mathrm{CeO}_{2}$ sublattice.

In Table II we list all the possible $\{111\}_{\mathrm{F}}$ surface periodicities of both ceria and reduced ceria bulk structures. In the case of fluorite $\mathrm{CeO}_{2}$, all $\{111\}_{\mathrm{F}}$ directions are equivalent and display a $1 \times 1$ periodicity. However, the formation of oxygen vacancies throughout the transition from $\mathrm{CeO}_{2}$ to $\mathrm{CeO}_{2-\delta}$ can destroy the equivalence among the $\{111\}_{\mathrm{F}}$ directions. In particular, for $\mathrm{Ce}_{11} \mathrm{O}_{20}$, this process gives rise to two nonequivalent families of $\{111\}_{\mathrm{F}}$ surfaces, namely, the $\sqrt{7} \times \sqrt{13}$ surfaces for two of the directions and the $\sqrt{3} \times \sqrt{31}$ surfaces for the two other ones. Similarly, $\mathrm{Ce}_{7} \mathrm{O}_{12}$ exhibits a $\sqrt{7} \times \sqrt{7}$ surface

TABLE I. Primitive vectors $\vec{a}_{1}, \vec{a}_{2}$, and $\vec{a}_{3}$ and location of oxygen vacancies for $\mathrm{Ce}_{11} \mathrm{O}_{20}, \mathrm{Ce}_{7} \mathrm{O}_{12}, \mathrm{Ce}_{3} \mathrm{O}_{5}$, and $C$-type $\mathrm{Ce}_{2} \mathrm{O}_{3}$ bulk structures. Primitive vectors are described in the fluorite unit-cell basis (denoted by the subscript F). Oxygen vacancy sites are stated in terms of the corresponding primitive vectors for each structure.

\begin{tabular}{lcccc}
\hline \hline & $\mathrm{Ce}_{11} \mathrm{O}_{20}$ & $\mathrm{Ce}_{7} \mathrm{O}_{12}$ & $\mathrm{Ce}_{3} \mathrm{O}_{5}$ & $C-\mathrm{Ce}_{2} \mathrm{O}_{3}$ \\
\hline$\vec{a}_{1}$ & $\frac{1}{2}[1 \overline{1} \overline{2}]_{\mathrm{F}}$ & $\frac{1}{2}[\overline{1} 12]_{\mathrm{F}}$ & $\frac{1}{2}[211]_{\mathrm{F}}$ & {$[200]_{\mathrm{F}}$} \\
$\vec{a}_{2}$ & $\frac{1}{2}[\overline{2} \overline{3} 1]_{\mathrm{F}}$ & $\frac{1}{2}[2 \overline{1} 1]_{\mathrm{F}}$ & $\frac{1}{2}[\overline{1} \overline{2} 1]_{\mathrm{F}}$ & {$[020]_{\mathrm{F}}$} \\
$\vec{a}_{3}$ & $\frac{1}{2}[\overline{2} 1 \overline{1}]_{\mathrm{F}}$ & $\frac{1}{2}[12 \overline{1}]_{\mathrm{F}}$ & $\frac{1}{2}[2 \overline{2} \overline{2}]_{\mathrm{F}}$ & {$[002]_{\mathrm{F}}$} \\
Vacancies & {$\left[\frac{1}{2} \frac{3}{4} \frac{1}{4}\right]$} & {$\left[\frac{3}{4} \frac{3}{4} \frac{3}{4}\right]$} & {$\left[00 \frac{5}{6}\right]$} & {$\left[\frac{n}{8} \frac{n}{8} \frac{n}{8}\right]^{\mathrm{a}}$} \\
& {$\left[\frac{1}{2} \frac{1}{4} \frac{3}{4}\right]$} & {$\left[\frac{1}{4} \frac{1}{4} \frac{1}{4}\right]$} & {$\left[\frac{2}{3} \frac{1}{3} \frac{1}{3}\right]$} & {$\left[\frac{i}{8} \frac{j}{8} \frac{k}{8}\right]^{\mathrm{b}}$} \\
& & & {$\left[\frac{1}{3} \frac{2}{3} \frac{1}{3}\right]$} & \\
\hline \hline
\end{tabular}

$\overline{{ }^{\mathrm{a}} n=1,3,5,7 \text { (four vacancies). }}$

${ }^{\mathrm{b}}(i, j, k)$ represent even permutations of three different numbers taken from the $[1,3,5,7]$ sequence (12 vacancies). 
TABLE II. Periodic reconstructions associated with their corresponding bulk structures of ceria and reduced ceria. The plane orientations are indicated using both the fluorite and the reduced phases primitive vectors. The last row indicates whether the corresponding surface structure was experimentally observed (along with the reference) or not.

\begin{tabular}{|c|c|c|c|c|c|c|c|c|}
\hline \multirow{2}{*}{$\begin{array}{l}\text { Bulk structures } \\
\text { Reconstructions }\end{array}$} & \multirow{2}{*}{$\begin{array}{l}\mathrm{CeO}_{2} \\
1 \times 1\end{array}$} & \multicolumn{2}{|c|}{$\mathrm{Ce}_{11} \mathrm{O}_{20}$} & \multicolumn{2}{|l|}{$\mathrm{Ce}_{7} \mathrm{O}_{12}$} & \multicolumn{2}{|c|}{$\mathrm{Ce}_{3} \mathrm{O}_{5}$} & \multirow{2}{*}{$\begin{array}{c}\mathrm{C}-\mathrm{Ce}_{2} \mathrm{O}_{3} \\
4 \times 4\end{array}$} \\
\hline & & $\sqrt{7} \times \sqrt{13}$ & $\sqrt{3} \times \sqrt{31}$ & $\sqrt{7} \times \sqrt{7}$ & $\sqrt{3} \times \sqrt{13}$ & $3 \times 3$ & $\sqrt{3} \times \sqrt{3}$ & \\
\hline \multirow[t]{4}{*}{ Orientations } & $(111)_{\mathrm{F}}$ & (121) & & (111) & & $(2 \overline{1} \overline{1})$ & & (111) \\
\hline & $(11 \overline{1})_{\mathrm{F}}$ & & $(1 \overline{3} 0)$ & & (1̄02) & $(1 \overline{2} 1)$ & & $(11 \overline{1})$ \\
\hline & $(1 \overline{1} 1)_{\mathrm{F}}$ & & $(01 \overline{2})$ & & $(02 \overline{1})$ & (111) & & $(1 \overline{1} 1)$ \\
\hline & $(1 \overline{1} \overline{1})_{\mathrm{F}}$ & $(20 \overline{1})$ & & & $(\overline{2} 10)$ & & $(001)$ & $(1 \overline{1} \overline{1})$ \\
\hline Observed & Yes & No & No & Yes $[42-44,46,48]$ & No & Yes [43-45] & Yes [48] & Yes [42-45] \\
\hline
\end{tabular}

periodicity in one of the $\{111\}_{\mathrm{F}}$ directions and a $\sqrt{3} \times \sqrt{13}$ surface in the other three. In the limit of high reduction, we find $C-\mathrm{Ce}_{2} \mathrm{O}_{3}$, which, due to its cubic structure, recovers the equivalence among the four $\{111\}_{\mathrm{F}}$ directions, displaying a unique $4 \times 4$ surface periodicity. Top views for the different surface phases, including the optimal location of the $\mathrm{Ce}^{3+}$ ions [21] are shown in Fig. 1. Further details of the surface terminations are described in Ref. [48].

As priorly mentioned, the experimentally observed $\sqrt{7} \times$ $\sqrt{7}[42,43,48]$ and $4 \times 4[42-45,63]$ periodicities can be related to known $\mathrm{CeO}_{2-\delta}$ stable bulk structures, i.e., $\mathrm{Ce}_{7} \mathrm{O}_{12}$ and $\mathrm{Ce}_{2} \mathrm{O}_{3}$ bixbyite, respectively, but, contrarily, the $3 \times 3$ [43-45], $3 \times \sqrt{7}$ [48], and $\sqrt{3} \times \sqrt{3}$ [48] periodicities cannot. Furthermore, there are three possible periodicities that have not yet been experimentally found in annealed ceria surfaces (cf. Table II), namely, the $\sqrt{7} \times \sqrt{13}$ and $\sqrt{3} \times \sqrt{31}$ reconstructions, corresponding to $\mathrm{Ce}_{11} \mathrm{O}_{20}$, as well as the $\sqrt{3} \times \sqrt{13}$ reconstruction, corresponding to $\mathrm{Ce}_{7} \mathrm{O}_{12}$ (see the Supplemental Material [62]). In the following, we will create and discuss computational models of reduced O-Ce-O trilayers with $3 \times 3, \sqrt{3} \times \sqrt{3}$, and $\sqrt{7} \times 3$ periodicities.

\section{B. (111) Surfaces not associated with stable $\mathrm{CeO}_{2-\delta}$ bulk phases}

In this section we focus on periodicities that have been experimentally observed but cannot be considered as surface terminations of any stable reduced ceria bulk structure, such as $3 \times 3, \sqrt{3} \times \sqrt{3}$, and $\sqrt{7} \times 3$. Taking into account that the outermost ceria layers are much more easily reduced than ceria bulk and that mixtures of subsurface and surface oxygen vacancies within the first $\mathrm{O}-\mathrm{Ce}-\mathrm{O}$ trilayer are energetically preferred over deeper layers $[17,26,68]$, we model these terminations considering, in the first place, one reduced ceria trilayer on an unreduced $\mathrm{CeO}_{2}$ (111) slab.

At this point it is important to revisit three ordering rules for oxygen vacancies in ceria, based on previous studies. First, it is well known that the effective repulsion between oxygen vacancies prevents the formation of vacancies at nearest-neighbor sites, i.e., at $\left\langle\frac{1}{2} 00\right\rangle_{\mathrm{F}}$ relative positions. In addition, it was suggested that pairs of vacancies try to avoid relative positions $\langle 100\rangle_{\mathrm{F}}$ and $\left\langle\frac{3}{2} 00\right\rangle_{\mathrm{F}}$, which correspond to the fourth and ninth neighbors in the anion sublattice, as in the case of the known stable bulk phases [21,32]. We will refer to the ordering of vacancies avoiding the formation of the first-, fourth-, and ninth-neighbor pairs as the first rule
(R1). Second, for ceria (111) surfaces, the lowest formation energy of isolated oxygen vacancies corresponds to sites at the subsurface oxygen layer, which leads to a tendency for the vacancies to accumulate in such a layer, even at high vacancy concentrations $[17,18,26,69]$. This constitutes the second ordering rule for vacancies (R2). Finally, a repulsion between pairs of vacancies in relative positions $\left\langle\frac{1}{2} \frac{1}{2} 0\right\rangle_{\mathrm{F}}$ at the subsurface oxygen layer has been previously observed [17,41]. This tendency to avoid first-neighbor vacancy pairs within the oxygen plane is represented by the third rule (R3). In this contribution, we first verify the validity of the mentioned rules by considering diverse vacancy configurations with $3 \times 3$ periodicity. Moreover, we note that the vacancy structures with periodicities $\sqrt{3} \times \sqrt{3}$ and $\sqrt{7} \times 3$ previously reported [48] also satisfy these rules.

As is well known, the localization of the excess charge created by oxygen vacancies in ceria, driving the $\mathrm{Ce}^{4+}$ to $\mathrm{Ce}^{3+}$ reduction, affects their formation energies. More precisely, $\mathrm{Ce}^{3+}$ sites which are next-nearest neighbors to the vacancies are the energetically most favorable ones $[15,17-19,21,25,26]$ and, at reduced ceria surfaces, $\mathrm{Ce}^{3+}$ ions prefer to localize in the outermost Ce layer $[15,17,18,26]$. Despite the $\mathrm{Ce}^{3+}$ preference to localize in the first Ce layer, when the density of $\mathrm{Ce}^{3+}$ ions is moderately high, some of the $\mathrm{Ce}^{3+}$ ions would rather localize in the second Ce layer [17]. This is because the $\mathrm{Ce}^{3+}$ ions would rather be in deeper layers than next to a vacancy. The driving force for adopting such configurations is the better ability of the system to relax lattice strain induced by the more spacious $\mathrm{Ce}^{3+}$ ion compared to its $\mathrm{Ce}^{4+}$ counterpart. The competition and interplay between the guidelines for the ordering of oxygen vacancies and $\mathrm{Ce}^{3+}$ ions, turns difficult the prediction of the lowest-energy structure for a given vacancy concentration and requests DFT $+U$ calculations of many different configurations for the vacancies, as well as of numerous $\mathrm{Ce}^{3+}$ configurations for each specified vacancy distribution; this is a formidable task. In the following, we focus first on the localization of the vacancies without predetermined excess charge localization and, once the lowest-energy vacancy arrangement at a given vacancy concentration is determined, we optimize the $\mathrm{Ce}^{3+}$ localization (cf. Sec. II).

\section{$3 \times 3$ periodicity}

Reduced (111) surfaces with $3 \times 3$ periodicity were observed in thin films using LEED techniques and different growing and annealing procedures as mentioned before $[43,45,47]$. 

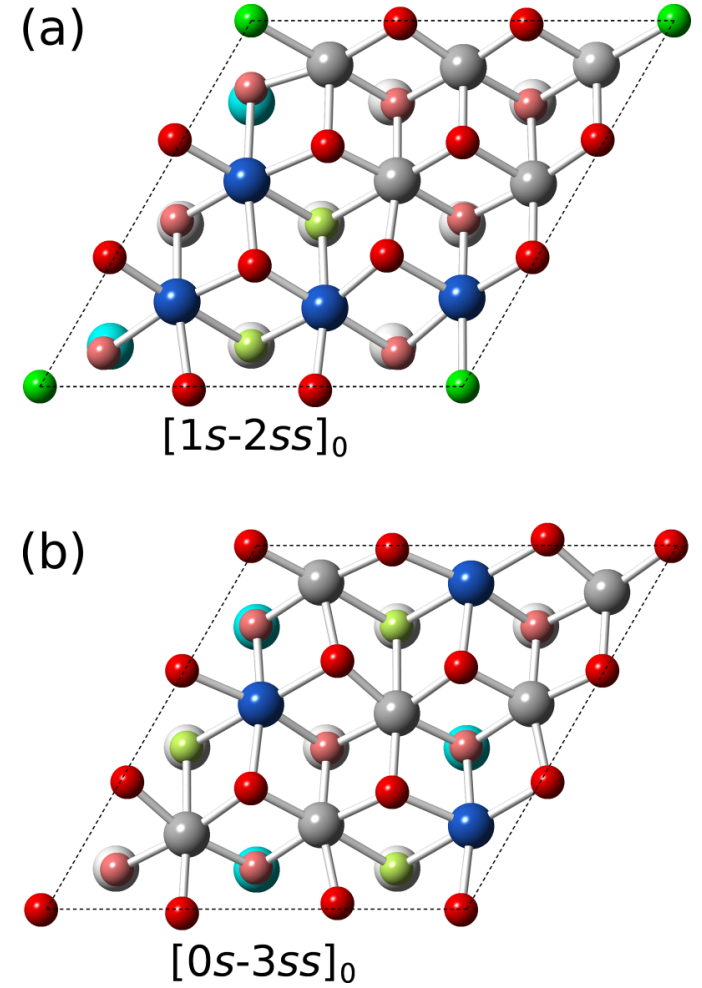

FIG. 2. The two most stable $3 \times 3 \mathrm{CeO}_{2-x}(111)$ structures with three vacancies in the first trilayer. The configuration with the lowest formation energy is depicted in (a) and has two vacancies at the subsurface layer and one vacancy at the surface one. (b) The structure with energy slightly above the lowest-energy one has all the vacancies located at the subsurface layer. Only the first atomic trilayer (O-Ce-O) and the second $\mathrm{Ce}$ layer are depicted for simplicity. The color coding for the atoms is the same as in Fig. $1 . \mathrm{Ce}^{4+}$ and $\mathrm{Ce}^{3+}$ ions in the second Ce layer are represented lighter than those in the first one.

According to these studies, the outermost reduced trilayer should have three vacancies within a $3 \times 3$ unit cell, i.e., a $\mathrm{Ce}_{3} \mathrm{O}_{5}$ stoichiometry. However, it is not clear from the experiments how these vacancies are precisely located within the overlayer.

In principle, there are 816 possibilities for generating three vacancies among the 18 oxygen atoms lying within the first surface trilayer, but only 26 of them are nonequivalent. These cases can be arranged in groups which we label as (ns-mss), where $n$ denotes the number of vacancies at the surface $(s)$ and $m$ stands for the subsurface $(s s)$ vacancies. The above-mentioned possibilities are then grouped in the families $(3 s-0 s s),(2 s-1 s s),(1 s-2 s s)$, and $(0 s-3 s s)$. A scheme for each structure within these families is presented in the Supplemental Material [62] alongside the vacancy formation energies calculated using DFT $+U$. These calculations were performed as indicated above, i.e., by initially letting the excess $\mathrm{Ce}^{3+}$ charge localize without a suggested initialization. Afterwards, several $\mathrm{Ce}^{3+}$ distributions were considered taking into account the $\mathrm{Ce}^{3+}$ localization guidelines outlined above.

The structure with the lowest average vacancy formation energy $E_{v}(2.03 \mathrm{eV})$ belongs to the $(1 s-2 s s)$ family, and we label it $[1 s-2 s s]_{0}$ [see Fig. 2(a)]. The next configuration, not far in energy from the previous one, corresponds to the
$(0 s-3 s s)$ family with $E_{v}=2.04 \mathrm{eV}$, and we name it $[0 s-3 s s]_{0}$ [Fig. 2(b)]. However, this last configuration should be ruled out from the list of potential candidates to explain the observed $3 \times$ 3 LEED diffraction pattern because it reduces to a $\sqrt{3} \times \sqrt{3}$ periodicity due to symmetry reasons. Regarding the preferred oxygen vacancy orderings, we note that the two mentioned lowenergy configurations present most of the vacancies located at the subsurface, in consonance with the tendency to accumulate vacancies in such an oxygen layer asserted by $\mathrm{R} 2$. These lowest-energy structures do not present pairs of vacancies at the distances given by the relative positions $\left\langle\frac{1}{2} 00\right\rangle_{\mathrm{F}},\langle 100\rangle_{\mathrm{F}}$, and $\left\langle\frac{3}{2} 00\right\rangle_{\mathrm{F}}$, in agreement with R1. Moreover, the vacancy configuration $[1 s-2 s s]_{0}$ is the only one within the $(1 s-2 s s)$ group without pairs of vacancies at those distances. Finally, we point out that $[0 s-3 s s]_{0}$ is the only structure within the $(0 s-3 s s)$ group fulfilling R3. The fact that the lowest-energy configurations tend to obey most of the vacancy ordering rules suggests that these rules should be taken into account when proposing the distribution of oxygen vacancies in reduced ceria. The validity of them is also corroborated when the energies of the whole set of possible distributions of three vacancies in the $3 \times 3$ unit cell are compared as discussed in detail in the Supplemental Material [62].

\section{$\sqrt{7} \times 3$ periodicity}

Recently, the unexpected oblique $\sqrt{7} \times 3$ periodicity on the reduced (111) ceria surface was observed for the first time by Olbrich et al. using noncontact AFM techniques [48]. In that work, by annealing in ultrahigh vacuum at $1020 \mathrm{~K}$, terraces with coexisting $\sqrt{7} \times 3$ and $\sqrt{7} \times \sqrt{7}$ surface domains were found, displaying a larger predominance of the $\sqrt{7} \times 3$ phase at the domain boundaries. This coexistence under the same reduction conditions suggests that the vacancy concentration of both phases should be similar. The $\sqrt{7} \times 3$ surface phase, being predominant in the border domains, should actually have a slightly larger vacancy concentration than the $\sqrt{7} \times \sqrt{7}$ one [48]. This last structure corresponds to a (111) termination of the $\mathrm{Ce}_{7} \mathrm{O}_{12}$ bulk, having a vacancy concentration of $2 / 7$ in the outermost surface trilayer, defined as the number of surface plus subsurface vacancies in the reduced layer divided by the total number of atoms in a nonreduced oxygen layer of the same cell. Therefore, to model a $\sqrt{7} \times 3$ trilayer, we consider a corresponding slightly higher concentration of $1 / 3$ in the outermost surface trilayer and choose three vacancies among the 18 oxygen sites. The precise distribution of vacancies and $\mathrm{Ce}^{3+}$ ions in this trilayer was obtained in a previous work using a combination of AFM images and theoretical analysis [48], yielding the structure shown in Fig. 3, which has one vacancy in the first oxygen layer and two vacancies in the second one [it belongs to the $(1 s-2 s s)$ family] without first-, fourth-, and ninth-neighbor vacancy pairs, in coincidence with the $3 \times 3$ trilayer and in agreement with the previously mentioned rules. Note that the $\sqrt{7} \times 3$ model has the same stoichiometry as the $3 \times 3$ periodicity, i.e., $\mathrm{Ce}_{3} \mathrm{O}_{5}$. This is consistent with the fact that both structures were observed under similar reducing conditions, although in different ceria films and using distinct experimental techniques [43,45,48]. In particular, the $\sqrt{7} \times 3$ structure was obtained in a bulklike 


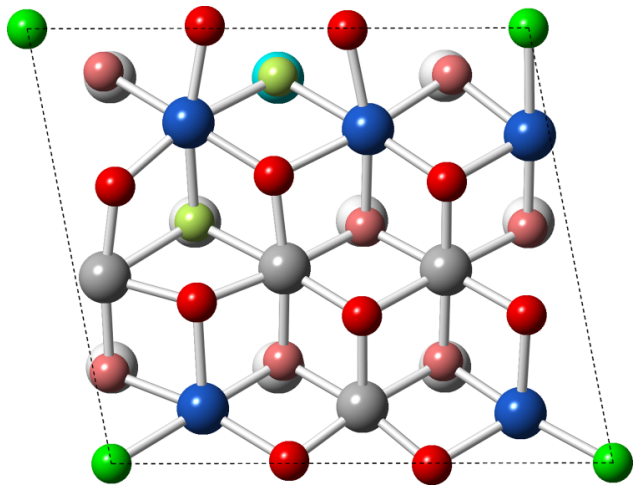

FIG. 3. Most stable $\sqrt{7} \times 3 \mathrm{CeO}_{2-x}(111)$ structure with three vacancies in the first trilayer. Only the first atomic trilayer (O-Ce-O) and the second Ce layer are depicted for simplicity. Color coding as in Fig. 2.

180-nm-thick film, whereas the $3 \times 3$ periodicity was found in thin films.

\section{$\sqrt{3} \times \sqrt{3}$ periodicity}

In the same theoretical-experimental work where the $\sqrt{7} \times 3$ surface periodicity was reported [48], (111) surface reconstructions of reduced ceria with $\sqrt{3} \times \sqrt{3}$ periodicity were also found at higher temperatures, concluding that such a surface does not present vacancies in the upper oxygen layer. The distribution of vacancies and $\mathrm{Ce}^{3+}$ ions was also obtained in the mentioned work [48], resulting in the structure shown in Fig. 4(c). In this last structure, the first two vacancies are placed at the subsurface oxygen layer according to R2, and a third vacancy is located in the third trilayer in order to fulfill R1. Note that the reduced ceria overlayer with a thickness equal to three $\mathrm{O}-\mathrm{Ce}-\mathrm{O}$ trilayers has a $\mathrm{Ce}_{3} \mathrm{O}_{5}$ stoichiometry. In the next section we show that this structure and the $3 \times 3$ one are actually different (111) terminations of the same quasistable reduced bulk structure.

\section{PROPOSAL OF A $\mathrm{Ce}_{3} \mathrm{O}_{5}$ BULK STRUCTURE}

Starting from the vacancy configurations of the trilayers with $\mathrm{Ce}_{3} \mathrm{O}_{5}$ stoichiometry introduced in the previous section, we gradually expand the overlayer by successively repeating the density of vacancies in each of the two oxygen layers of the next trilayers. To locate the new vacancies, we avoid pairs of vacancies at the distances given by the relative positions $\left\langle\frac{1}{2} 00\right\rangle_{\mathrm{F}},\langle 100\rangle_{\mathrm{F}}$, and $\left\langle\frac{3}{2} 00\right\rangle_{\mathrm{F}}$, taking into account $\mathrm{R} 1$.

For the $3 \times 3$ periodicity, there is a unique way of extending the reduced overlayer from two to three oxygen layers; the newly added oxygen layer has one vacancy. The next step is to remove two oxygen atoms from the fourth oxygen layer. There are three possibilities to accommodate these two vacancies, and we choose the one that produces a second reduced trilayer similar to the first one, namely, a rigid translation of the first trilayer along the $[11 \overline{1}]_{\mathrm{F}}$ direction [see Fig. 4(a)]. Afterwards, we continue piling up identical reduced trilayers along the $[11 \overline{1}]_{\mathrm{F}}$ direction to obtain a reduced overlayer with the desired thickness. With this procedure, we generate a bulk arrangement with $\mathrm{Ce}_{3} \mathrm{O}_{5}$ stoichiometry as depicted in Fig. 4(b). This bulk structure has not yet been experimentally observed, and therefore, it is expected that it should only be stable for thin overlayers. The structures in Fig. 4 show also the optimized positions of the $\mathrm{Ce}^{3+}$ ions.

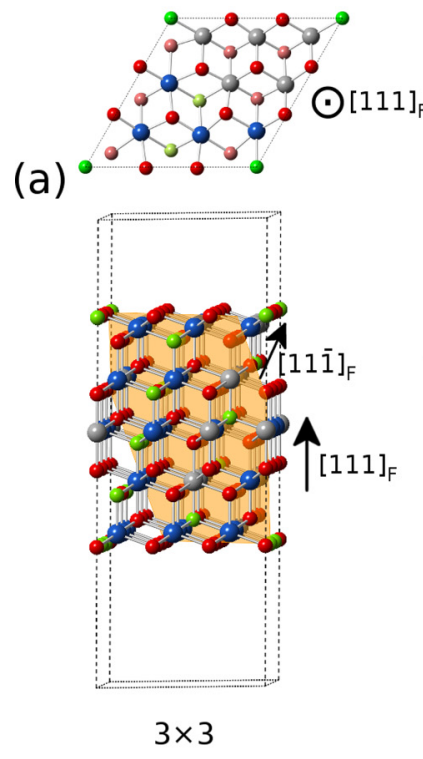

(b)

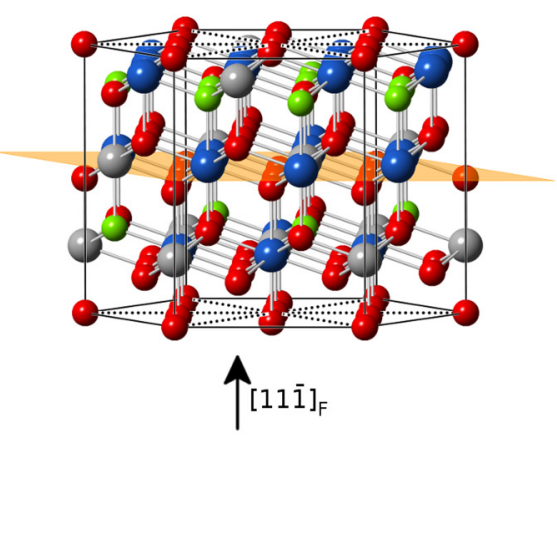

(c)
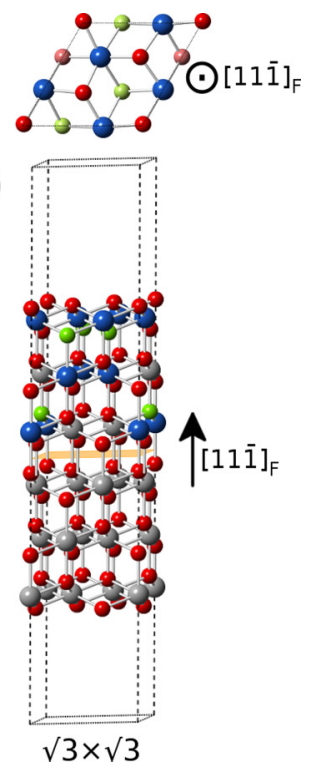

FIG. 4. Extension of the $3 \times 3$ reduced trilayer to thicker overlayers towards a $\mathrm{Ce}_{3} \mathrm{O}_{5}$ bulk structure. (a) Starting from the topmost trilayer of the $3 \times 3$ slab, the density of the vacancies is gradually extended to more trilayers as explained in the text. The resulting structure consists of a piling of reduced trilayers along the $[11 \overline{1}]_{\mathrm{F}}$ direction in the fluorite basis. This $\mathrm{Ce}_{3} \mathrm{O}_{5}$ bulk structure has trigonal symmetry, and its $[11 \overline{1}]_{\mathrm{F}}$ planes exhibit the $\sqrt{3} \times \sqrt{3}$ periodicity. (b) The $\mathrm{Ce}_{3} \mathrm{O}_{5}$ unit cell with a symmetry axis along the $[11 \overline{1}]_{\mathrm{F}}$ direction highlights the $\sqrt{3} \times \sqrt{3}$ periodicity. This cell presents the same distribution of vacancies and $\mathrm{Ce}^{3+}$ ions as the primitive cell of the $\sqrt{3} \times \sqrt{3}$ reduced overlayer pictured in (c). Color coding as in Fig. 1. The $[11 \overline{1}]_{\mathrm{F}}$ plane orientation is highlighted in orange for the three cases. 
In the following we discuss the geometry and stability of this $\mathrm{Ce}_{3} \mathrm{O}_{5}$ bulk, which has trigonal symmetry $(P 31 \mathrm{~m})$. It is interesting to note that the $C_{3 v}$ symmetry axis of this structure lies in the $[11 \overline{1}]_{\mathrm{F}}$ direction and that the crystalline planes $(11 \overline{1})_{\mathrm{F}}$ have $\sqrt{3} \times \sqrt{3}$ periodicity, in coincidence with one of those experimentally observed for reduced ceria surfaces. In addition, both crystalline $(1 \overline{1} 1)_{\mathrm{F}}$ and $(1 \overline{1} \overline{1})_{\mathrm{F}}$ planes exhibit the same $3 \times 3$ periodicity as the original $(111)_{\mathrm{F}}$ ceria surface [cf. Fig. 4(a)]. This means that surface terminations of the $\mathrm{Ce}_{3} \mathrm{O}_{5}$ bulk in three of the $\{111\}_{\mathrm{F}}$ directions would exhibit $3 \times 3$ periodicity, whereas in the fourth one, it would be $\sqrt{3} \times \sqrt{3}$ (see Table II). It is noteworthy that the conventional cell of the proposed $\mathrm{Ce}_{3} \mathrm{O}_{5}$ structure [Fig. 4(b)] presents exactly the same vacancy distribution as that of the thin reduced ceria layer with $\sqrt{3} \times \sqrt{3}$ periodicity previously discussed [Fig. 4(c)], allowing for an explanation of the observed $3 \times 3$ and $\sqrt{3} \times \sqrt{3}$ reconstructions as terminations of this $\mathrm{Ce}_{3} \mathrm{O}_{5}$ bulk structure.

In order to study the stability of the $\mathrm{Ce}_{3} \mathrm{O}_{5}$ bulk structure, we calculate its average vacancy formation energy $\left(E_{v}=\right.$ $2.56 \mathrm{eV}$ ) performing an ionic relaxation within the fixed primitive cell, i.e., with a unit cell as derived from the fluorite structure (noted as $\mathrm{Ce}_{3} \mathrm{O}_{5}$-like, cf. Sec. II). In Fig. 5(a) this formation energy is compared with those of known bulk phases, such as $\mathrm{Ce}_{11} \mathrm{O}_{20}, \mathrm{Ce}_{7} \mathrm{O}_{12}$, and $C-\mathrm{Ce}_{2} \mathrm{O}_{3}$ and with those of a wide set of nonstable bulk structures with different degrees of reduction $\left(\mathrm{Ce}_{32} \mathrm{O}_{63}, \mathrm{Ce}_{32} \mathrm{O}_{62}, \mathrm{Ce}_{8} \mathrm{O}_{15}, \mathrm{Ce}_{8} \mathrm{O}_{14}\right)$, diverse distributions of vacancies, and $\mathrm{Ce}^{3+}$ ions, that were calculated in our previous work (cf. Ref. [21]). In this figure, all formation energies correspond to $\left(\mathrm{Ce}_{x} \mathrm{O}_{y}\right.$-like) structures where the ionic positions have been relaxed keeping the primitive cell derived from the fluorite structure fixed. Thus, these cells are not fully relaxed, and consequently their total energies are slightly higher than those of corresponding fully relaxed structures $\left(\mathrm{Ce}_{x} \mathrm{O}_{y}\right.$ real, cf. Sec. II) [21]. Inspection of Fig. 5(a) shows that the average vacancy formation energy of the $\mathrm{Ce}_{3} \mathrm{O}_{5}$-like structure is slightly larger than those of the known stable phases, for example, it lies $0.08 \mathrm{eV}$ above that of the $C-\mathrm{Ce}_{2} \mathrm{O}_{3}$-like structure, but it is notoriously lower (at least $0.24 \mathrm{eV}$ ) than those corresponding to nonstable structures.

To compare the stability of the found $\mathrm{Ce}_{3} \mathrm{O}_{5}$ bulk structure with that of the known stable ones as a function of the reduction conditions, we perform a full structural relaxation optimizing ionic positions as well as the volume and shape of the unit cell $\left(\mathrm{Ce}_{x} \mathrm{O}_{y}\right.$ real). In Fig. 5(b) we show the stability plot in terms of the Gibbs free energy per unit volume of the known stable $\mathrm{Ce}_{11} \mathrm{O}_{20^{-}}, \mathrm{Ce}_{7} \mathrm{O}_{12^{-}}$, and $\mathrm{Ce}_{2} \mathrm{O}_{3}$-real structures along with the $\mathrm{Ce}_{3} \mathrm{O}_{5}$-real one. This plot shows that the $\mathrm{Ce}_{3} \mathrm{O}_{5}$-real bulk structure is not the most stable phase for any value of the oxygen chemical potential, but its low average vacancy formation energy suggests that this bulk structure could be considered as a quasistable phase. We further calculate the density of states and the phonon dispersion relations along selected high-symmetry directions in the Brillouin zone for this $\mathrm{Ce}_{3} \mathrm{O}_{5}$ phase; no unstable (imaginary frequency) phonon mode was found (see Sec. S3 of the Supplemental Material [62]).

As mentioned in the Introduction, a $C$-type $\mathrm{Ce}_{2} \mathrm{O}_{3+\delta}$ structure with a stoichiometry close to $\mathrm{Ce}_{3} \mathrm{O}_{5}$ was reported in the
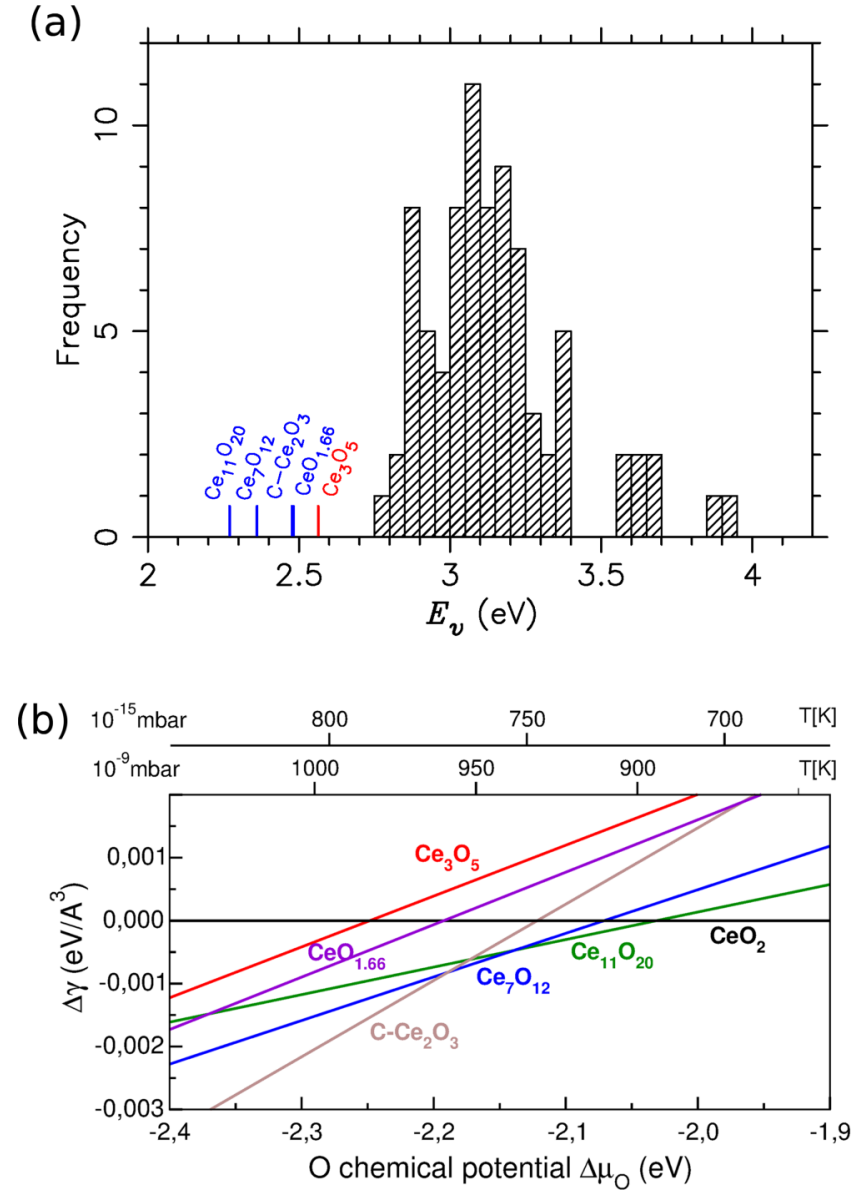

FIG. 5. (a) Histogram for the formation energies $\left(E_{v}\right)$ for a wide set of reduced bulk ceria structures [21] with a concentration of vacancies ranging from $1.6 \%$ to $12.5 \%$ without relaxing the lattice parameters. (b) Stability plot for the fully relaxed $\mathrm{Ce}_{3} \mathrm{O}_{5}$ bulk phase along with the known bulk phases $\mathrm{CeO}_{2}, \mathrm{Ce}_{11} \mathrm{O}_{20}, \mathrm{Ce}_{7} \mathrm{O}_{12}, C-\mathrm{Ce}_{2} \mathrm{O}_{3}$, and $C-\mathrm{Ce}_{2} \mathrm{O}_{3+\delta}$ with stoichiometry $\mathrm{CeO}_{1.66}$.

literature [27,32]. To evaluate the stability of such a structure, we model a bixbyite-like structure selecting 11 out of the 16 oxygen vacancies in a $C-\mathrm{Ce}_{2} \mathrm{O}_{3}$-like unit cell, leading to a $\mathrm{Ce}_{32} \mathrm{O}_{53}\left(\mathrm{CeO}_{1.66}\right)$ stoichiometry. $E_{v}$ of this last structure is by about $80(5) \mathrm{meV}$ smaller (larger) than that of the $\mathrm{Ce}_{3} \mathrm{O}_{5}-$ like (C-Ce $\mathrm{O}_{3}$-like) structure [cf. Fig. 5(a)]. After full lattice relaxation is considered, the difference between the $E_{v}$ values of the $C-\mathrm{Ce}_{2} \mathrm{O}_{3+\delta}$-real and $\mathrm{Ce}_{3} \mathrm{O}_{5}$-real structures is reduced to approximately $60 \mathrm{meV}$ [cf. Fig. 5(b)]. However, there is an important difference regarding the possible bulk terminations of these two structures in the $\{111\}_{\mathrm{F}}$ directions. The $\mathrm{Ce}_{3} \mathrm{O}_{5}$ structure can explain both the $\sqrt{3} \times \sqrt{3}$ and the $3 \times 3$ observed terminations whereas the $C-\mathrm{Ce}_{2} \mathrm{O}_{3+\delta}$ cannot. The reported $\sqrt{3} \times \sqrt{3}$ and the $3 \times 3$ periodicities could then be due to the formation of thin layers of the here proposed $\mathrm{Ce}_{3} \mathrm{O}_{5}$ phase, which, although it is not a stable bulk phase, could increase its stability near the surface.

The $\sqrt{7} \times 3$ oblique surface reconstruction discussed above has the same degree of reduction as the proposed quasistable $\mathrm{Ce}_{3} \mathrm{O}_{5}$ bulk structure, but this periodicity does not correspond to any of the $\{111\}_{\mathrm{F}}$ bulk terminations of this crystal structure. Following the same method employed for the $3 \times 3$ 
(a)

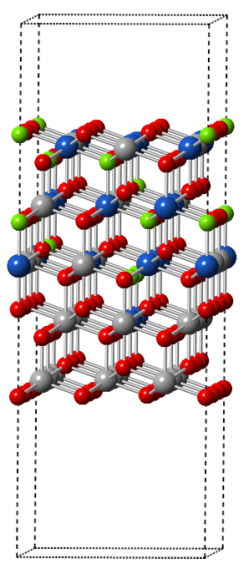

(b)

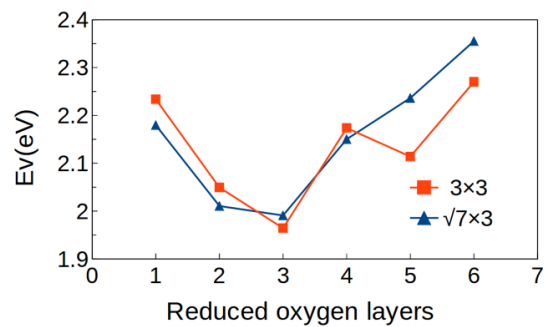

FIG. 6. (a) Extension of the $\sqrt{7} \times 3$ trilayer to thicker overlayer terminations. This procedure can be performed up to the sixth oxygen layer (see the text). (b) Average formation energy for $3 \times 3$ (red squares) and $\sqrt{7} \times 3$ (blue triangles) terminations as a function of the number of reduced oxygen layers. The color coding of the atoms is the same as in Fig. 1.

reconstruction, we tried to extend the $3 \times \sqrt{7}$ trilayer towards a possible new bulk structure, but in this case the continuation procedure can be performed only up to the sixth oxygen layer (i.e., three O-Ce-O trilayers) as shown in Fig. 6(a). Beyond this depth, no oxygen vacancies can be accommodated without violating the ordering rule $\mathrm{R} 1$ and, therefore, it is not possible to extend this surface into another $\mathrm{Ce}_{3} \mathrm{O}_{5}$ bulk phase.

In Fig. 6(b), we compare the average vacancy formation energy for the $3 \times 3$ termination of $\mathrm{Ce}_{3} \mathrm{O}_{5}$ with the one corresponding to the $\sqrt{7} \times 3$ periodicity, considering overlayers of up to the allowed six oxygen layers. It can be observed that, for overlayers thinner than three oxygen layers, the formation energy favors the oblique reconstruction, whereas for wider reduced overlayers, the $3 \times 3$ termination is the preferred one. This result could imply that this thin $\sqrt{7} \times 3$ reconstruction cannot be observed for characterization techniques which use information coming from beyond the first trilayer (e.g., LEED) and this could be the reason for it being observed only using non-noncontact AFM techniques [48].

Summarizing, we find that $3 \times 3$ and $\sqrt{3} \times \sqrt{3}$ reconstructions of (111)-oriented ceria surfaces can be understood as $\{111\}_{\mathrm{F}}$ terminations of a quasistable $\mathrm{Ce}_{3} \mathrm{O}_{5}$ bulk phase in a similar way as the $\sqrt{7} \times \sqrt{7}$ and $4 \times 4$ reconstructions are terminations of the $\mathrm{Ce}_{7} \mathrm{O}_{12}$ and $C-\mathrm{Ce}_{2} \mathrm{O}_{3}$ stable bulk phases, respectively. In contrast, the oblique reconstruction can only be stabilized for thinner reduced overlayers and cannot be associated with any quasistable bulk phase.

\section{CONCLUSIONS}

In this paper we have undertaken the task of providing a global and unified picture to describe reconstructions of (111)oriented ceria surfaces with different degrees of reduction. Some reconstructions cannot be attributed to reduced stable bulk phases, namely, the $3 \times 3$, the $\sqrt{3} \times \sqrt{3}$, and the $\sqrt{7} \times 3$ ones. However, we found that the first two mentioned recon- structions can be associated with the same quasistable ceria bulk structure with $\mathrm{Ce}_{3} \mathrm{O}_{5}$ stoichiometry, which is reported here. The proposed $\mathrm{Ce}_{3} \mathrm{O}_{5}$ bulk structure is not the most stable phase for any value of temperature and oxygen pressure, although a thin overlayer of this reduced termination can be stabilized. This overlayer become less stable as its thickness is increased. This bulk phase is clearly more stable than a wide range of other nonstable reduced ceria bulk structures having a variety of vacancy concentrations, defect distributions, and cell geometries, whereas the known $\mathrm{Ce}_{7} \mathrm{O}_{12}, \mathrm{Ce}_{11} \mathrm{O}_{20}$, and $C-\mathrm{Ce}_{2} \mathrm{O}_{3}$ bulk phases are the only structures we found that are more stable than the $\mathrm{Ce}_{3} \mathrm{O}_{5}$ one.

Through systematic total energy calculations for all possible vacancy distributions, we obtained the most stable $3 \times 3$ reduced ceria trilayer on $\mathrm{CeO}_{2}$ (111) compatible with experimental results and verified the validity of simple vacancy ordering rules. The $\mathrm{Ce}_{3} \mathrm{O}_{5}$ bulk structure was constructed as a gradual extension of the reduced $3 \times 3$ trilayer into deeper layers by fixing the density of vacancies in the newly reduced trilayers and avoiding pairs of vacancies at the distances given by the relative positions $\left\langle\frac{1}{2} 00\right\rangle_{\mathrm{F}},\langle 100\rangle_{\mathrm{F}}$, and $\left\langle\frac{3}{2} 00\right\rangle_{\mathrm{F}}$. Following the same method, we found that the $\sqrt{7} \times 3$ overlayer cannot generate a bulk structure, but it can be extended for up to three trilayers. The instability of thicker $\sqrt{7} \times 3$ layers can explain the fact that this periodicity, recently observed using noncontact AFM microscopy, has not been detected with LEED techniques.

Our results provide a unified picture on how to describe reconstructions of reduced ceria surfaces as terminations of the bulk structures from which they derive when these bulks exist. In this context, we have also suggested the existence of a quasistable $\mathrm{Ce}_{3} \mathrm{O}_{5}$ structure that could be experimentally confirmed. Although real catalysts are powders exhibiting different facets and surface terminations, the rules found in this paper for the distribution of oxygen vacancies as well as for the excess charge localization will still be obeyed. For instance, the excess charge will always prefer not to localize in nearestneighbor cationic sites to a vacancy, and first-neighboring subsurface vacancies will be avoided if possible. Such detailed knowledge is essential for the understanding of ceria-based materials in catalysis as well as to the modeling of reaction mechanisms on their surfaces. Summarizing, the insight here obtained has fundamental and practical implications for understanding the geometry and electronic structures of reduced ceria surfaces which is of great importance to tailor their functionality in applications.

\section{ACKNOWLEDGMENTS}

We thank MINECO (Grant No. CTQ2015-71823-R), ANPCyT (Grants No. PICT-1555 and No. PICT-0867), and CONICET (Grants No. PIP-0038 and No. PIP-00273) for financial support. Computer time provided by CESGA, CAC-CNEA, SGAI-CSIC, BSC, University of Cantabria-IFCA, and BIFIZCAM, and Instituto de Astrofísica de La Palma as well as support from the COST Action Grant No. CM1104 are thankfully acknowledged. The collaboration with our colleagues R. Olbrich and M. Reichling (University Osnabrück, Germany) as well as C. Barth (Aix-Marseille University, France), who performed experimental work, is gratefully acknowledged. 
[1] A. Trovarelli, Catal. Rev.: Sci. Eng. 38, 439 (1996).

[2] Q. Fu, H. Saltsburg, and M. Flytzani-Stephanopoulos, Science 301, 935 (2003).

[3] U. Tumuluri, G. Rother, and Z. Wu, Ind. Eng. Chem. Res. 55, 3909 (2016).

[4] G. Vilé, B. Bridier, J. Wichert, and J. Pérez-Ramírez, Angew. Chem., Int. Ed. 51, 8620 (2012).

[5] R. J. Gorte, AIChE J. 56, 1126 (2010).

[6] H.-W. Jen, G. W. Graham, W. Chun, R. W. McCabe, J.-P. Cuif, S. E. Deutsch, and O. Touret, Catal. Today 50, 309 (1999).

[7] H. Gandhi, G. Graham, and R. McCabe, J. Catal. 216, 433 (2003).

[8] J. Conesa, A. Martínez-Arias, M. Fernández-García, and J. Soria, Res. Chem. Intermediat. 26, 103 (2000).

[9] S. Park, J. M. Vohs, and R. J. Gorte, Nature (London) 404, 265 (2000).

[10] C. Xia, Y. Li, Y. Tian, Q. Liu, Z. Wang, L. Jia, Y. Zhao, and Y. Li, J. Power Sources 195, 3149 (2010).

[11] P. Jasinski, T. Suzuki, and H. U. Anderson, Sens. Actuators, B 95, 73 (2003).

[12] F. Pourfayaz, Y. Mortazavi, A. Khodadadi, and S. Ajami, Sens. Actuators B 130, 625 (2008).

[13] A. G. Khairnar and A. M. Mahajan, Bull. Mater. Sci. 36, 259 (2013).

[14] X. Sun, B. Sun, L. Liu, N. Xu, X. Liu, R. Han, J. Kang, G. Xiong, and T. P. Ma, IEEE Electron Device Lett. 30, 334 (2009).

[15] J.-F. Jerratsch, X. Shao, N. Nilius, H.-J. Freund, C. Popa, M. V. Ganduglia-Pirovano, A. M. Burow, and J. Sauer, Phys. Rev. Lett. 106, 246801 (2011).

[16] J. Paier, C. Penschke, and J. Sauer, Chem. Rev. 113, 3949 (2013).

[17] G. E. Murgida and M. V. Ganduglia-Pirovano, Phys. Rev. Lett. 110, 246101 (2013)

[18] M. V. Ganduglia-Pirovano, J. L. F. Da Silva, and J. Sauer, Phys. Rev. Lett. 102, 026101 (2009).

[19] H.-Y. Li, H.-F. Wang, X.-Q. Gong, Y.-L. Guo, Y. Guo, G. Lu, and P. Hu, Phys. Rev. B 79, 193401 (2009).

[20] Y. Pan, N. Nilius, H. J. Freund, J. Paier, C. Penschke, and J. Sauer, Phys. Rev. Lett. 111, 206101 (2013).

[21] G. E. Murgida, V. Ferrari, M. V. Ganduglia-Pirovano, and A. M. Llois, Phys. Rev. B 90, 115120 (2014).

[22] G. E. Murgida, V. Vildosola, V. Ferrari, and A. M. Llois, Solid State Commun. 152, 368 (2012).

[23] H.-F. Wang, Y.-L. Guo, G.-Z. Lu, and P. Hu, Angew. Chem., Int. Ed. 48, 8289 (2009).

[24] B. Wang, X. Xi, and A. N. Cormack, Chem. Mater. 26, 3687 (2014).

[25] M. V. Ganduglia-Pirovano, G. E. Murgida, V. Ferrari, and A. M. Llois, J. Phys. Chem. C 121, 21080 (2017).

[26] J. E. Sutton, A. Beste, and S. H. Overbury, Phys. Rev. B 92, 144105 (2015).

[27] D. Bevan, J. Inorg. Nucl. Chem. 1, 49 (1955).

[28] D. Bevan and J. Kordis, J. Inorg. Nucl. Chem. 26, 1509 (1964).

[29] R. Körner, M. Ricken, J. Nölting, and I. Riess, J. Solid State Chem. 78, 136 (1989).

[30] J. Zhang, Z. Kang, and L. Eyring, J. Alloys Compd. 192, 57 (1993).

[31] G. Adachi and N. Imanaka, Chem. Rev. 98, 1479 (1998).

[32] E. Kümmerle and G. Heger, J. Solid State Chem. 147, 485 (1999).
[33] J. Carrasco, G. Vilé, D. Fernández-Torre, R. Pérez, J. PérezRamírez, and M. V. Ganduglia-Pirovano, J. Phys. Chem. C 118, 5352 (2014).

[34] M. García-Melchor, L. Bellarosa, and N. López, ACS Catal. 4 , 4015 (2014).

[35] M. V. Ganduglia-Pirovano, Catalysis Today 253, 20 (2015).

[36] Z. Liu, D. C. Grinter, P. G. Lustemberg, T.-D. Nguyen-Phan, Y. Zhou, S. Luo, I. Waluyo, E. J. Crumlin, D. J. Stacchiola, and J. Zhou, Angew. Chem., Int. Ed. 55, 7455 (2016).

[37] P. G. Lustemberg, P. J. Ramírez, Z. Liu, R. A. Gutiérrez, D. G. Grinter, J. Carrasco, S. D. Senanayake, J. A. Rodriguez, and M. V. Ganduglia-Pirovano, ACS Catal. 6, 8184 (2016).

[38] Z. Liu, P. Lustemberg, R. A. Gutiérrez, J. J. Carey, R. M. Palomino, M. Vorokhta, D. C. Grinter, P. J. Ramírez, V. Matolín, M. Nolan et al., Angew. Chem., Int. Ed. 56, 13041 (2017).

[39] H. Nörenberg and G. A. D. Briggs, Phys. Rev. Lett. 79, 4222 (1997).

[40] F. Esch, S. Fabris, L. Zhou, T. Montini, C. Africh, P. Fornasiero, G. Comelli, and R. Rosei, Science 309, 752 (2005).

[41] S. Torbrügge, M. Reichling, A. Ishiyama, S. Morita, and O. Custance, Phys. Rev. Lett. 99, 056101 (2007).

[42] H. Wilkens, O. Schuckmann, R. Oelke, S. Gevers, M. Reichling, A. Schaefer, M. Bäumer, M. Zoellner, G. Niu, and T. Schroeder, Phys. Chem. Chem. Phys. 15, 18589 (2013).

[43] T. Duchoň, F. Dvořák, M. Aulická, V. Stetsovych, M. Vorokhta, D. Mazur, K. Veltruská, T. Skála, J. Mysliveček, I. Matolínová, and V. Matolin, J. Phys. Chem. C 118, 357 (2013).

[44] T. Duchoň, F. Dvořák, M. Aulická, V. Stetsovych, M. Vorokhta, D. Mazur, K. Veltruská, T. Skála, J. Mysliveček, I. Matolínová, and V. Matolin, J. Phys. Chem. C 118, 5058 (2014).

[45] J. Höcker, T. O. Menteş, A. Sala, A. Locatelli, T. Schmidt, J. Falta, S. D. Senanayake, and I. Flege, Adv. Mater. Interfaces 2 , 1500314 (2015).

[46] H. Wilkens, O. Schuckmann, R. Oelke, S. Gevers, A. Schaefer, M. Bäumer, M. Zoellner, T. Schroeder, and J. Wollschläger, Appl. Phys. Lett. 102, 111602 (2013).

[47] P. Luches, F. Pagliuca, and S. Valeri, Phys. Chem. Chem. Phys. 16, 18848 (2014).

[48] R. Olbrich, G. E. Murgida, V. Ferrari, C. Barth, A. M. Llois, M. Reichling, and M. V. Ganduglia-Pirovano, J. Phys. Chem. C 121, 6844 (2017).

[49] J. P. Perdew, K. Burke, and M. Ernzerhof, Phys. Rev. Lett. 77, 3865 (1996).

[50] VASP.5.2.12 [http://www.vasp.at/].

[51] S. L. Dudarev, G. A. Botton, S. Y. Savrasov, C. J. Humphreys, and A. P. Sutton, Phys. Rev. B 57, 1505 (1998).

[52] M. Cococcioni and S. de Gironcoli, Phys. Rev. B 71, 035105 (2005).

[53] S. Fabris, G. Vicario, G. Balducci, S. de Gironcoli, and S. Baroni, J. Phys. Chem. B 109, 22860 (2005).

[54] D. A. Andersson, S. I. Simak, B. Johansson, I. A. Abrikosov, and N. V. Skorodumova, Phys. Rev. B 75, 035109 (2007).

[55] C. W. M. Castleton, J. Kullgren, and K. Hermansson, J. Chem. Phys. 127, 244704 (2007).

[56] M. Nolan, J. E. Fearon, and G. W. Watson, Solid State Ionics 177, 3069 (2006).

[57] Z. Yang, T. K. Woo, and K. Hermansson, J. Chem. Phys. 124, 224704 (2006).

[58] P. R. L. Keating, D. O. Scanlon, and G. W. Watson, J. Phys.: Condens. Matter 21, 405502 (2009). 
[59] J. L. F. Da Silva, M. V. Ganduglia-Pirovano, J. Sauer, V. Bayer, and G. Kresse, Phys. Rev. B 75, 045121 (2007).

[60] D. Du, M. J. Wolf, K. Hermansson, and P. Broqvist, Phys. Rev. B 97, 235203 (2018).

[61] CRC Handbook of Chemistry and Physics, 76th ed., edited by D. R. Lide and H. P. Frederiske, (CRC, Boca Raton, FL, 1995).

[62] See Supplemental Material at http://link.aps.org/supplemental/ 10.1103/PhysRevMaterials.2.083609 for detailed results and discussions about the $(3 \times 3)-\mathrm{Ce}_{3} \mathrm{O}_{5} / \mathrm{CeO}_{2}(111)$ structures with three vacancies, stability plot for the reduced $\mathrm{Ce}_{x} \mathrm{O}_{y} / \mathrm{CeO}_{2}(111)$ surface phases, and relative stability of the $(\sqrt{7} \times \sqrt{13})$ - and $(\sqrt{3} \times \sqrt{31})-\mathrm{Ce}_{11} \mathrm{O}_{20} / \mathrm{CeO}_{2}(111)$ as well as of the $(\sqrt{7} \times$ $\sqrt{7})$ - and $(\sqrt{3} \times \sqrt{13})-\mathrm{Ce}_{7} \mathrm{O}_{12} / \mathrm{CeO}_{2}(111)$ structures along with atomic fractional coordinates, density of states, and phonon dispersion relations along selected high-symmetry directions in the Brillouin zone for the $\mathrm{Ce}_{3} \mathrm{O}_{5}$-real bulk structure together with atomic fractional coordinates.

[63] J. Höcker, J. O. Krisponeit, T. Schmidt, J. Falta, and J. I. Flege, Nanoscale 9, 9352 (2017).

[64] U. Berner and K. D. Schierbaum, Phys. Rev. B 65, 235404 (2002).

[65] W. Xiao, Q. Guo, and E. Wang, Chem. Phys. Lett. 368, 527 (2003).

[66] S. Ray and D. Cox, J. Solid State Chem. 15, 333 (1975).

[67] E. Schweda and Z. C. Kang, in Binary Rare Earth Oxides, edited by G. Adachi, N. Imanaka, and Z. C. Kang (Springer, Dordrecht, The Netherlands, 2005), p. 57.

[68] Z. Yang, T. K. Woo, M. Baudin, and K. Hermansson, J. Chem. Phys. 120, 7741 (2004).

[69] D. C. Grinter, R. Ithnin, C. L. Pang, and G. Thornton, J. Phys. Chem. C 114, 17036 (2010). 